\title{
ChemComm
}

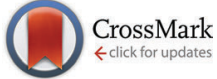

Cite this: Chem. Commun., 2016, 52, 10012

Received 1st June 2016

Accepted 12th July 2016

DOI: $10.1039 / c 6 c c 04610 j$

www.rsc.org/chemcomm

\section{Neutral versus polycationic coordination cages: a comparison regarding neutral guest inclusion $\dagger$}

\author{
György Szalóki, Vincent Croué, Magali Allain, Sébastien Goeb* and Marc Sallé*
}

\begin{abstract}
A neutral self-assembled container synthesized from a concave $\pi$-extended tetrathiafulvalene (exTTF) ligand and the cis-Pd(dctfb) 2 (cod) complex (dctfb = 3,5-dichloro-2,4,6-trifluorobenzene; $\operatorname{cod}=$ 1,5-cyclooctadiene) is described. This molecular host exhibits a good binding ability for fused polyaromatic substrates. The corresponding inclusion properties are compared with those of a previously described analogous octacationic cage, offering therefore the opportunity to address the effect of the cavity charge state over the binding of neutral molecules.
\end{abstract}

The preparation of molecular cages able to encapsulate ionic or neutral organic guests constitutes a major challenge for various applications ranging from selective depollution, reactivity in confined environments, or guest transport. In this context, the coordination-driven self-assembly strategy has been successfully used to build, in a straightforward way, more and more sophisticated metalla-cages, ${ }^{1}$ including electro-active ones. ${ }^{2}$ Being most often prepared by the reaction of a polypyridyl ligand (typically di-, tri- or tetra-pyridyl) with a metal cation, they generally correspond to polycationic cages. ${ }^{1,3}$ On this basis, we showed recently that the cationic coordination-cage $\mathbf{M}_{4} \mathbf{L}_{2}{ }^{{ }^{+}+}$(Scheme 1 and Fig. $2 b$ ) is able to bind the $\mathrm{B}_{12} \mathrm{~F}_{12}{ }^{2-}$ guest in a reversible way through a redox-driven assembly/disassembly process. ${ }^{4}$ Host-guest interactions are by nature more challenging to address in the case of neutral guests, which renders the design of appropriate receptors more delicate. On these grounds, an efficient redox control of the binding mode ${ }^{5,6}$ has been recently demonstrated from a tetracationic organic covalent receptor. When considering neutral guests, the polycationic character of the cages usually obtained through coordination-driven self-assembly may

Laboratoire MOLTECH-Anjou, Université d'Angers, CNRS UMR 6200,

2 bd Lavoisier, 49045 Angers Cedex, France. E-mail: sebastien.goeb@univ-angers.fr, marc.salle@univ-angers.fr

$\dagger$ Electronic supplementary information (ESI) available: Detailed synthesis protocols, experimental methods, X-ray diffraction studies and additional spectroscopic data for ligand $\mathbf{L}$ and complexes $\mathbf{M}_{4} \mathbf{L}_{2}$ and $\mathbf{M}_{4} \mathbf{L}_{2}{ }^{{ }^{+}}$. CCDC 1441971 and 1441826. For ESI and crystallographic data in CIF or other electronic format see DOI: $10.1039 / \mathrm{c} 6 \mathrm{cc} 04610 \mathrm{j}$ hamper both the kinetics and the thermodynamics of the binding, in particular because of the presence of highly competitive counter anions which obstruct the cavity. ${ }^{1 m, 7}$ On this basis, the design of neutral receptors through the self-assembled metal-driven strategy appears promising. Examples of neutral discrete metalla-assemblies are known and are synthetized either from the reaction of an anionic donating ligand (typically bearing carboxylate groups) and a cationic metal center, ${ }^{8}$ or from the reaction between a neutral ligand and a neutral metallic precursor. $^{1 m, 7}$ Some data related to the binding ability of such a neutral coordination cage for neutral guests have already been provided. ${ }^{7}$ Nevertheless, to the best of our knowledge, no comparative experimental study is available which addresses in a quantitative manner the binding affinity of a neutral guest for a charged coordination cage versus a neutral one, whereas this issue has already been reported in the case of an ionic guest. ${ }^{9}$ Such a comparative study, which is of importance for a better understanding of intermolecular forces which govern the recognition phenomena, needs to define a proper cavity whose geometry and size are the same for both the neutral and cationic states.

We describe herein a metal-directed neutral self-assembled cage $\mathbf{M}_{\mathbf{4}} \mathbf{L}_{\mathbf{2}}$ constructed from a tetra-pyridyl exTTF ligand and a neutral cis-oriented square planar bis-aryl palladium complex (cis-Pd(dctfb $)_{2}$ (cod)). ${ }^{10}$ The resulting assembly offers a unique opportunity to quantitatively compare the binding affinities of planar polyaromatic guests for two similar cavities $\left(\mathbf{M}_{4} \mathbf{L}_{2}\right.$ and $\left.\mathbf{M}_{4} \mathbf{L}_{2}{ }^{{ }^{8+}}\right)$ (Scheme 1) which essentially differ in the charge state of the metal center and therefore in the presence, or not, of counter anions. ${ }^{11}$

The tetrapyridyl-exTTF ligand $\mathbf{L}$ (Scheme 1) was synthesized in three steps from 2,3,6,7-tetrahydroxyanthracene-9,10-dione, in a $57 \%$ overall yield as previously described. ${ }^{4}$ The presence of the four peripheral triethylene glycol (TEG) chains on the anthracene core ensures the solubility of the resulting cages in various solvents. The self-assembly reaction of ligand $\mathbf{L}$ and complex cis-Pd(dctfb) ${ }_{2}$ (cod) was carried out for $48 \mathrm{~h}$ in acetone at room temperature. The reaction converged into a single discrete compound $\mathbf{M}_{4} \mathbf{L}_{2}$ (Scheme 1) that could be isolated in $87 \%$ yield via simple filtration. 

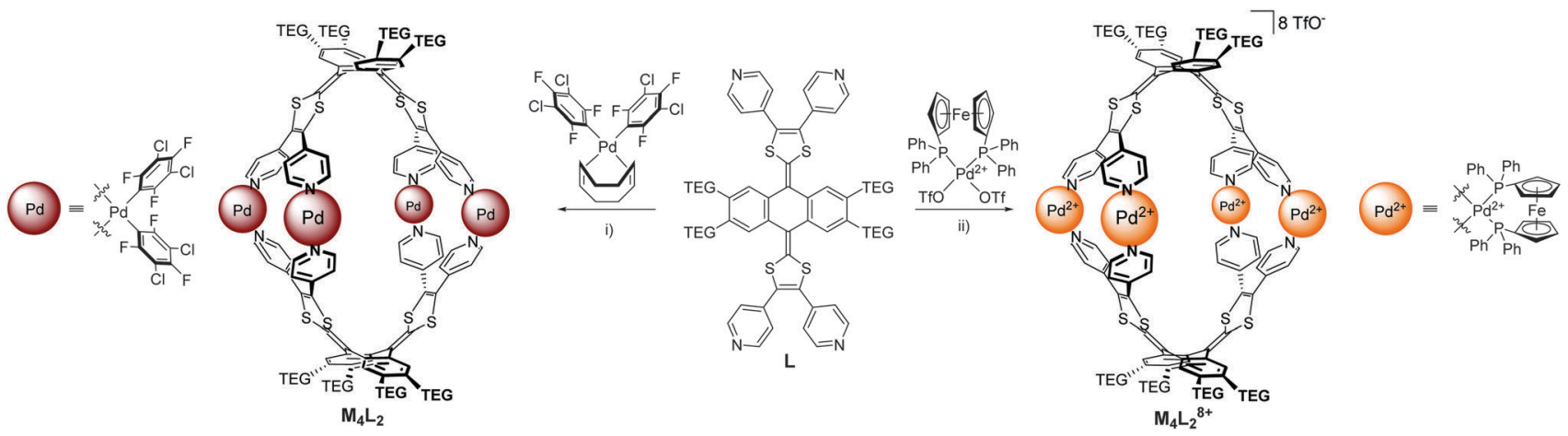

Scheme 1 Synthesis of cage $\mathbf{M}_{\mathbf{4}} \mathbf{L}_{\mathbf{2}}$ and $\mathbf{M}_{\mathbf{4}} \mathbf{L}_{\mathbf{2}}{ }^{8+}$. (i) Acetone, rt, $48 \mathrm{~h}, 87 \%$; (ii) nitromethane, $40{ }^{\circ} \mathrm{C}, 5 \mathrm{~min}, 83 \%$.

The complex $\mathbf{M}_{4} \mathbf{L}_{2}$ presents a high field shift of the $\alpha$ and $\beta$ pyridyl signals in the ${ }^{1} \mathrm{H}$ NMR spectrum compared to ligand $\mathbf{L}$ (Fig. 1a, b and Fig. S1, ESI + ), as expected from the coordination to the metal center. ${ }^{1} \mathrm{H}$ DOSY NMR exhibits only one alignment of signals with an extracted $D$ value of $3.22 \times 10^{-10} \mathrm{~m}^{2} \mathrm{~s}^{-1}$ in $\mathrm{CD}_{3} \mathrm{NO}_{2} / \mathrm{CDCl}_{3}(1 / 1)$ and $3.35 \times 10^{-10} \mathrm{~m}^{2} \mathrm{~s}^{-1}$ in $\mathrm{CDCl}_{3}$ (Fig. S3 and S4, ESI $\dagger$ ) and confirms the formation of only one discrete species. The corresponding hydrodynamic radius ${ }^{12}$ estimated from the Stokes-Einstein equation ${ }^{13}(T=298 \mathrm{~K})$ is of $11.4 \AA$, a value which is in accordance with the formation of a $\mathbf{M}_{4} \mathbf{L}_{2}$ species. ESI-FTICR mass spectrometry experiments carried out with $\mathbf{M}_{4} \mathbf{L}_{2}$ are silent due to the lack of charges. Taking advantage of the well-known ability of TEG chains to bind alkaline cations, an excess of KOTf (8 equivalents) was added to a solution of $\mathbf{M}_{4} \mathbf{L}_{2}$ ( $\left.C=2 \times 10^{-3} \mathrm{M}, \mathrm{CH}_{2} \mathrm{Cl}_{2} / \mathrm{CH}_{3} \mathrm{NO}_{2} 5 / 5\right)$ before ionization. Thus, the generated ionic species could be studied and confirmed the stoichiometry of the complex, as illustrated by characteristic multi-charged peaks $\left[\mathbf{M}_{4} \mathbf{L}_{2} \cdot(\mathrm{KOTf})_{4}-4 \mathrm{OTf}\right]^{4+}(\mathrm{m} / \mathrm{z}=1213.94)$ and $\left[\mathbf{M}_{4} \mathbf{L}_{2} \cdot(\mathrm{KOTf})_{4}{ }^{-3 \mathrm{OTf}}\right]^{3+}(\mathrm{m} / \mathrm{z}=1668.58)$ as well as by the good accordance between the experimental and the theoretical isotopic patterns (Fig. S5, ESI $\dagger$ ).

Single crystals of $\mathbf{M}_{4} \mathbf{L}_{2}$ could be grown by slow diffusion of acetonitrile in a chloroform solution and an XRD experiment confirmed the formation of a $\mathbf{M}_{4} \mathbf{L}_{2}$ cage (Fig. 2a and Fig. S30, ESI $\dagger$ ) which exhibits an internal ovoid cavity of $c a .15 \AA$ length over $13 \AA$ width, close to that of $\mathbf{M}_{4} \mathbf{L}_{2}{ }^{8+}(c a .15 .5 \AA \times 11.5 \AA)$ (Fig. 2b). ${ }^{14}$ This shape similitude offers a unique opportunity to compare the ability of these respectively neutral and charged metalla-cages for encapsulating a neutral guest, since they essentially differ by (i) their charge state on the metal and by (ii) the presence $\left(\mathbf{M}_{4} \mathbf{L}_{2}{ }^{8+}\right)$ or absence $\left(\mathbf{M}_{4} \mathbf{L}_{2}\right)$ of counter anions. In a previous work, we demonstrated that a polycationic cage, similar to $\mathbf{M}_{4} \mathbf{L}_{2}{ }^{8+}$ but devoid of peripheral TEG chains, allows the inclusion of perylene according to a $1: 1$ stoichiometry in nitromethane. ${ }^{15}$

We therefore studied the inclusion of different neutral fused polyaromatic guests into the ovoid cavities of $\mathbf{M}_{\mathbf{4}} \mathbf{L}_{\mathbf{2}}$ and $\mathbf{M}_{4} \mathbf{L}_{2}{ }^{8+}$ by ${ }^{1} \mathrm{H}$ NMR and ${ }^{1} \mathrm{H}$ DOSY NMR. A solvent mixture $\left(\mathrm{CD}_{3} \mathrm{NO}_{2} / \mathrm{CDCl}_{3} 1 / 1\right)$ has to be used in order to ensure the solubility of all the species and to allow a comparative study. As an illustrative example of the respective behavior of the neutral and the charged cages upon encapsulation, the ${ }^{1} \mathrm{H}$ NMR binding study of coronene is shown in Fig. 1. Importantly, whereas only a slight difference is observed for $\mathbf{M}_{4} \mathbf{L}_{2}{ }^{8+}$ upon addition of one equivalent of the guest (Fig. $1 b^{\prime}$ and $d^{\prime}$ ), the ${ }^{1} \mathrm{H}$ NMR signals of metalla-cage $\mathbf{M}_{4} \mathbf{L}_{2}$ and of coronene are

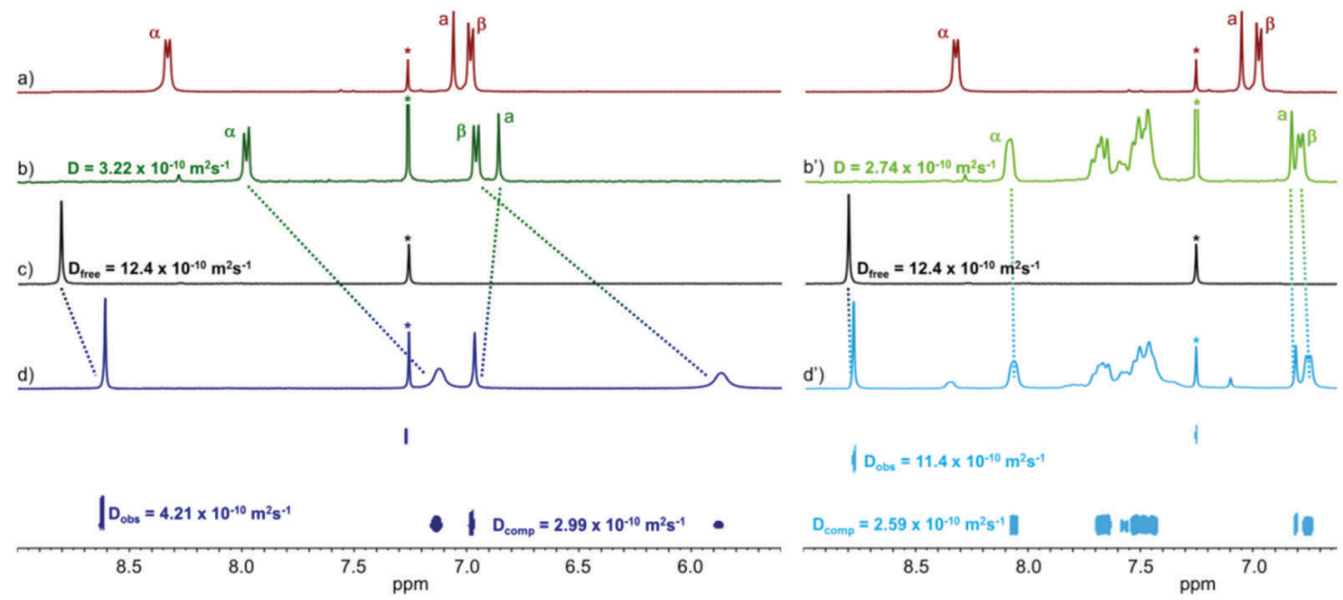

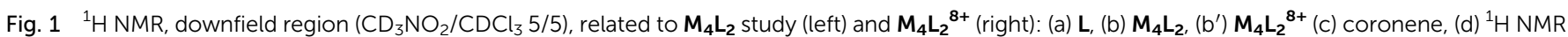
and corresponding ${ }^{1} \mathrm{H}$ DOSY NMR of a mixture of $\mathbf{M}_{4} \mathrm{~L}_{2}$ and coronene $\left(1 / 1, C=2 \times 10^{-3} \mathrm{M}\right),\left(\mathrm{d}^{\prime}\right){ }^{1} \mathrm{H}$ NMR and corresponding ${ }^{1} \mathrm{H}$ DOSY NMR of a mixture of $\mathrm{M}_{4} \mathrm{~L}_{2}{ }^{8+}$ and coronene $\left(1 / 1, \mathrm{C}=2 \times 10^{-3} \mathrm{M}\right)$. 


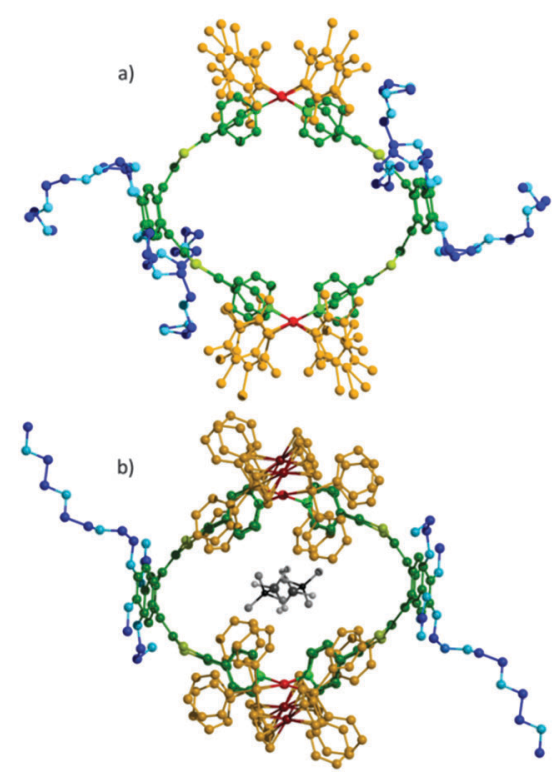

Fig. 2 X-Ray crystal structures of the host structure $\mathbf{M}_{4} \mathbf{L}_{2}$ (a) and $\mathbf{M}_{4} \mathbf{L}_{2}{ }^{8+}$ (b). For $\mathbf{M}_{4} \mathrm{~L}_{2}{ }^{8+}$, triflate anions located inside the cavity are represented (in grey). Colors used for both $\mathbf{M}_{\mathbf{4}} \mathbf{L}_{\mathbf{2}}$ and $\mathbf{M}_{\mathbf{4}} \mathbf{L}_{\mathbf{2}}{ }^{\mathbf{}}$ : : exTTF skeleton (green), PEG chains (blue), Pd complex (orange).

significantly high-field shifted (Fig. 1b-d). The binding is accompanied in the case of $\mathbf{M}_{4} \mathbf{L}_{2}$ by a significant decrease of the coronene diffusion coefficient $D$ value $\left(D=4.21 \times 10^{-10} \mathrm{~m}^{2} \mathrm{~s}^{-1}\right.$ vs. $D_{\text {free }}=12.40 \times 10^{-10} \mathrm{~m}^{2} \mathrm{~s}^{-1}$ ) in the ${ }^{1} \mathrm{H}$ DOSY NMR spectrum (Fig. 1c and d). In contrast, the coronene $D$ value remains almost unchanged in the presence of $\mathbf{M}_{4} \mathbf{L}_{2}{ }^{8+}\left(D=11.40 \times 10^{-10} \mathrm{~m}^{2} \mathrm{~s}^{-1}\right.$ vs. $D_{\text {free }}=12.40 \times 10^{-10} \mathrm{~m}^{2} \mathrm{~s}^{-1}$ ). As already demonstrated for the charged cage, the formation of a 1/1 host-guest complex was also found via a Job Plot analysis for $\mathbf{M}_{\mathbf{4}} \mathbf{L}_{2}$ (Fig. S32, ESI $\dagger$ ). From these ${ }^{1} \mathrm{H}$ DOSY NMR data, $K_{\mathrm{a}}$ binding constants of $2.6 \times 10^{4}\left(\mathbf{M}_{4} \mathbf{L}_{2}\right)$ and $63\left(\mathbf{M}_{4} \mathbf{L}_{2}{ }^{{ }^{+}}\right)$could be calculated (see $\mathrm{ESI} \dagger$ for details), meaning a ratio of $c a .400$ in favor of the neutral cage. The complexation of other planar aromatic guests was studied and their respective binding constants are compiled in Table 1. As it can be noted from these values, the binding abilities increase with the guest size and, remarkably, the neutral $\mathbf{M}_{4} \mathbf{L}_{2}$ cage systematically presents a higher affinity (one to several orders of magnitude higher) for the tested neutral polyaromatic guests. These results clearly demonstrate the positive effect of the absence of charges and of anions on the periphery of the ovoid cavity, for the encapsulation of neutral guests. ${ }^{16}$ Increasing the

Table 1 Calculated binding constants $K_{a}$ for cages $\mathbf{M}_{\mathbf{4}} \mathbf{L}_{\mathbf{2}}{ }^{\mathbf{8}}$ and $\mathbf{M}_{\mathbf{4}} \mathbf{L}_{\mathbf{2}}$ towards planar polyaromatic guests as estimated from ${ }^{1} \mathrm{H}$ DOSY NMR experiments in $\mathrm{CD}_{3} \mathrm{NO}_{2} / \mathrm{CDCl}_{3}$ at $298 \mathrm{~K}\left(\mathrm{C}=2 \times 10^{-3} \mathrm{M}\right)$

\begin{tabular}{llcl}
\hline Guest & Solvent $\left(\mathrm{CD}_{3} \mathrm{NO}_{2} / \mathrm{CDCl}_{3}\right)$ & $\mathbf{M}_{\mathbf{4}} \mathbf{L}_{2}{ }^{8+}$ & $\mathbf{M}_{\mathbf{4}} \mathbf{L}_{\mathbf{2}}$ \\
\hline Coronene & $8 / 2$ & $170^{b}$ & $1.1 \times 10^{5}$ \\
& $5 / 5$ & 63 & $2.6 \times 10^{4}$ \\
Perylene & $5 / 5$ & 96 & $4.0 \times 10^{3}$ \\
Triphenylene & $5 / 5$ & $a$ & $2.8 \times 10^{2}$ \\
Pyrene & $5 / 5$ & & $1.7 \times 10^{2}$ \\
& & &
\end{tabular}

${ }^{a}$ No binding could be detected under these conditions. ${ }^{b} C=10^{-3} \mathrm{M}$.

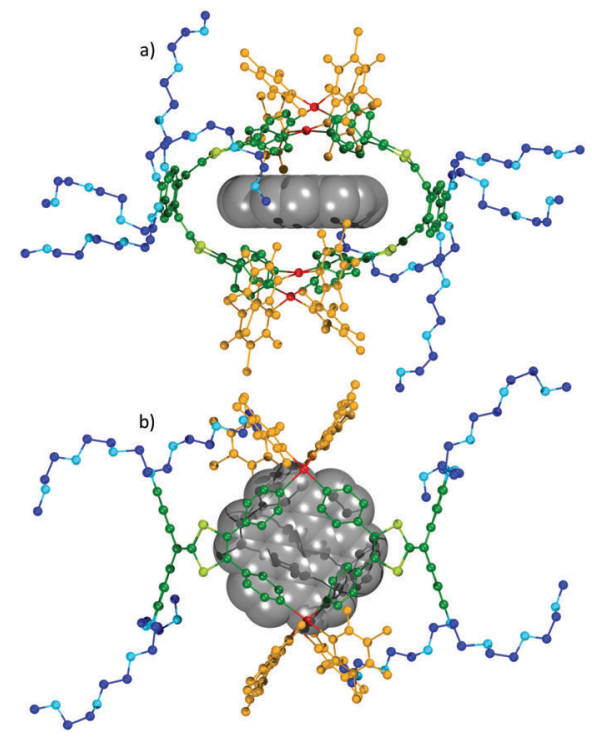

Fig. 3 X-Ray crystal structure of coronene $\subset \mathbf{M}_{\mathbf{4}} \mathbf{L}_{\mathbf{2}}$ (a) side view, (b) top view. Colors used: exTTF skeleton (green), PEG chains (blue), Pd complex (orange), coronene (grey).

proportion of nitromethane (a poor solvent for the guest under consideration) in the solvent mixture results in a significant increase of the binding constant $\left(K_{\mathrm{a}}=1.1 \times 10^{5}\right.$ with $\mathbf{M}_{4} \mathbf{L}_{2}$ and coronene). Single crystals of the coronene $\subset \mathbf{M}_{4} \mathbf{L}_{2}$ inclusion complex could be grown at room temperature from the latter solvent mixture. The XRD experiment confirms the encapsulation of one coronene unit located in the middle of the cavity defined by the exTTF concave fragments containing both 1,3-dithiol rings (Fig. 3). It is worth noting that in order to maximize the host-guest interactions, the Pd-Pd distances are significantly reduced upon complexation related to the free cage $\mathbf{M}_{4} \mathbf{L}_{2}$, as can be seen from the cavity size which changes from $15 \AA \times 13 \AA$ (Fig. 2 a) to $16 \AA \times 10.5 \AA$ in coronene $\subset \mathbf{M}_{4} \mathbf{L}_{2},{ }^{14}$ illustrating the unexpectedly flexible character of the cavity. Binding studies of coronene with the $\mathbf{M}_{4} \mathbf{L}_{2}{ }^{8+}$ assembly subjected to a $\mathrm{TfO}^{-}$anion exchange (i.e. $\mathrm{BF}_{4}{ }^{-}$and $\mathrm{B}_{12} \mathrm{~F}_{12}{ }^{2-}$ ) were carried out and monitored by ${ }^{1} \mathrm{H}$ DOSY NMR in $\mathrm{CD}_{3} \mathrm{NO}_{2} / \mathrm{CDCl}_{3} 8 / 2$. $K_{\mathrm{a}}$ values of 200 and 58 were found for $\mathrm{BF}_{4}{ }^{-}$and $\mathrm{B}_{12} \mathrm{~F}_{12}{ }^{2-}$ respectively (170 for $\mathrm{TfO}^{-}$) (Fig. S12, S27 and S28, ESI $\dagger$ ) showing that the nature of the counter anion does influence the binding of the coronene guest and justify the superiority of the neutral host over the polycationic one. Finally, an inclusion control study was led by ${ }^{19} \mathrm{~F}$ DOSY NMR experiments with the $\mathrm{B}_{12} \mathrm{~F}_{12}{ }^{2-}$ anion (Fig. S29-S31, ESI $\dagger$ ). $K_{\mathrm{a}}$ values of 25 and $>10^{6}$ were obtained for $\mathbf{M}_{4} \mathbf{L}_{2}$ and $\mathbf{M}_{4} \mathbf{L}_{2}{ }^{{ }^{+}+}$respectively, confirming that the polycationic cage binds much more strongly anionic guests than the neutral one does.

In summary, an electron-rich exTTF-based $\mathbf{M}_{4} \mathbf{L}_{2}$ neutral cage which exhibits a good ability to bind planar polyaromatic guests in a 1:1 stoichiometry was synthesized. This neutral assembly could be compared to the previously described analogous $\mathbf{M}_{4} \mathbf{L}_{2}{ }^{8+}$ system, which essentially differs in the charges on the metal and therefore by the presence of counter anions surrounding the cavity. This comparative experimental study affords first quantitative evidence 
of the superiority of neutral hosts for the binding of neutral guests (with $K_{\mathrm{a}}$ values which are one to several orders of magnitude higher in this study), an observation which is of importance for the rational design of strong host/guest systems in future. On these grounds, the design of new neutral metalla-cages appears highly relevant. ${ }^{7}$ In particular, the present work illustrates the promising perspectives offered by the square planar cis-Pd(dctfb $)_{2}(\operatorname{cod})$ complex $^{10}$ for preparing neutral cages upon interaction with various poly-pyridyl ligands, in a straightforward way and under mild conditions. Therefore, the scope of this approach can in principle be extended to most of the abundant poly-pyridyl ligands available in the literature and previously used to build polycationic cages.

This work has been supported by the ANR JCJC program (ANR-14-CE08-0001 BOMBER). The authors gratefully acknowledge the MENRT for a PhD grant (VC). They also acknowledge Dr I. Freuze and B. Siegler (PIAM, Univ. Angers), as well as Drs F. Aubriet and V. Carré (CNRS-Univ. Lorraine (TGE "FT-ICR")) for their assistance in spectroscopic analyses and finally Drs P. Fertey and S. Ravy (Synchrotron Soleil - CRISTAL beamline - project 20130173).

\section{Notes and references}

1 (a) For recent reviews see: N. Ahmad, H. A. Younus, A. H. Chughtai and F. Verpoort, Chem. Soc. Rev., 2015, 44, 9; (b) A. J. McConnell, C. S. Wood, P. P. Neelakandan and J. R. Nitschke, Chem. Rev., 2015, 115, 7729; (c) S. Zarra, D. M. Wood, D. A. Roberts and J. R. Nitschke, Chem. Soc. Rev., 2015, 44, 419; (d) M. Han, D. M. Engelhard and G. H. Clever, Chem. Soc. Rev., 2014, 43, 1848; (e) S. Mukherjee and P. S. Mukherjee, Chem. Commun., 2014, 50, 2239; $(f)$ T. R. Cook, V. Vajpayee, M. H. Lee, P. J. Stang and K.-W. Chi, Acc. Chem. Res., 2013, 46, 2464; $(g)$ K. Harris, D. Fujita and M. Fujita, Chem. Commun., 2013, 49, 6703; (h) A. Mishra, S. C. Kang and K.-W. Chi, Eur. J. Inorg. Chem., 2013, 5222; (i) M. M. J. Smulders, I. A. Riddell, C. Browne and J. R. Nitschke, Chem. Soc. Rev., 2013, 42, 1728; (j) M. D. Ward and P. R. Raithby, Chem. Soc. Rev., 2013, 42, 1619; (k) H. Amouri, C. Desmarets and J. Moussa, Chem. Rev., 2012, 112, 2015; $(l)$ T. R. Cook, Y.-R. Zheng and P. J. Stang, Chem. Rev., 2012, 113, 734; $(m)$ R. Chakrabarty, P. S. Mukherjee and P. J. Stang, Chem. Rev., 2011, 111, 6810; (n) L. R. MacGillivray, Angew. Chem.,
Int. Ed., 2012, 51, 1110; (o) Y. Inokuma, M. Kawano and M. Fujita, Nat. Chem., 2011, 3, 349; (p) S. De, K. Mahata and M. Schmittel, Chem. Soc. Rev., 2010, 39, 1555; (q) P. Jin, S. J. Dalgarno and J. L. Atwood, Coord. Chem. Rev., 2010, 254, 1760; $(r)$ Y.-F. Han, W.-G. Jia, W.-B. Yu and G.-X. Jin, Chem. Soc. Rev., 2009, 38, 3419; $(s)$ B. H. Northrop, Y.-R. Zheng, K.-W. Chi and P. J. Stang, Acc. Chem. Res., 2009, 42, 1554; ( $t$ ) P. J. Stang, J. Org. Chem., 2009, 74, 2; (u) B. Therrien, Eur. J. Inorg. Chem., 2009, 2445; (v) M. Yoshizawa, J. K. Klosterman and M. Fujita, Angew. Chem., Int. Ed., 2009, 48, 3418; (w) M. W. Cooke, D. Chartrand and G. S. Hanan, Coord. Chem. Rev., 2008, 252, 903; $(x)$ S. J. Dalgarno, N. P. Power and J. L. Atwood, Coord. Chem. Rev., 2008, 252, 825; (y) B. H. Northrop, D. Chercka and P. J. Stang, Tetrahedron, 2008, 64, 11495.

2 V. Croué, S. Goeb and M. Sallé, Chem. Commun., 2015, 51, 7275.

3 For anionic metalla-cages, see also: $(a)$ D. L. Caulder and K. N. Raymond, Acc. Chem. Res., 1999, 32, 975; (b) Z. J. Wang, C. J. Brown, R. G. Bergman, K. N. Raymond and F. D. Toste, J. Am. Chem. Soc., 2011, 133, 7358.

4 V. Croué, S. Goeb, G. Szalóki, M. Allain and M. Sallé, Angew. Chem., Int. Ed., 2016, 55, 1746.

5 M. Frasconi, I. R. Fernando, Y. Wu, Z. Liu, W.-G. Liu, S. M. Dyar, G. Barin, M. R. Wasielewski, W. A. Goddard and J. F. Stoddart, J. Am. Chem. Soc., 2015, 137, 11057.

6 For a redox-based switching of guest binding performed upon stimulating the guest, see e.g. W.-Y. Sun, T. Kusukawa and M. Fujita, J. Am. Chem. Soc., 2002, 124, 11570.

7 P. Thanasekaran, C.-H. Lee and K.-L. Lu, Coord. Chem. Rev., 2014, 280, 96.

8 N. Ahmad, A. H. Chughtai, H. A. Younus and F. Verpoort, Coord. Chem. Rev., 2014, 280, 1.

9 J. Kuwabara, C. L. Stern and C. A. Mirkin, J. Am. Chem. Soc., 2007, 129, 10074 .

10 L. J. Marshall and J. de Mendoza, Org. Lett., 2013, 15, 1548.

11 Note in addition that, whereas $\mathbf{M}_{4} \mathbf{L}_{2}$ involves two detfb (3,5-dichloro2,4,6-trifluorobenzene) as Pd co-ligands, $\mathbf{M}_{4} \mathbf{L}_{2}{ }^{8+}$ involves dppf.

12 Calculated from the experiment led in a pure solvent $\left(\mathrm{CDCl}_{3}\right)$ (Fig. S3, ESI $\dagger$ ), for which the viscosity of the medium is known.

13 (a) Y. Cohen, L. Avram and L. Frish, Angew. Chem., Int. Ed., 2005, 44, 520; (b) L. Avram and Y. Cohen, Chem. Soc. Rev., 2015, 44, 586.

14 The cavity size values are obtained by measuring the distance between (i) the opposite central anthracene rings on one hand and (ii) two opposite palladium atoms on the other hand.

15 S. Bivaud, S. Goeb, V. Croué, P. I. Dron, M. Allain and M. Sallé, J. Am. Chem. Soc., 2013, 135, 10018.

16 Performing the binding studies at a similar ionic strength for $\mathbf{M}_{4} \mathbf{L}_{\mathbf{2}}{ }^{\mathbf{}}{ }^{\mathbf{2}}$ and $\mathbf{M}_{4} \mathbf{L}_{2}$, by addition of 8 equivalents of tetrabutylammonium trifluoromethane-sulfonate in the latter case, does not change the result. 